\title{
Calculation of Selenium Isotope Fractionation using Density Functional Theory
}

\author{
HEATHER K. SHRIMPTON ${ }^{1}$, MARCEL NOOIJEN ${ }^{2}$, CAROL \\ PTACEK $^{1}$, DAVID W. BLOWES ${ }^{1}$ \\ ${ }^{1}$ Department of Earth and Environmental Sciences, University \\ of Waterloo, Waterloo, Ontario, Canada \\ ${ }^{1}$ Department of Chemistry, University of Waterloo, Waterloo, \\ Ontario, Canada
}

Selenium is an important nutrient required in trace amounts, but becomes toxic at higher concentrations. Many aquatic species are more sensitive to Se contamination than humans [1], making it important to avoid discharge of Se into sensitive environments. Measuring and tracking Se bearing plumes in groundwater can prove difficult, due to the complex nature of subsurface contaminant transport processes. Delineating the mechanisms involved in attenuating Se in subsurface environments is highly important in determining whether a continuous source may still pose an environmental hazard. This work seeks to predict these mechanisms using stable isotope measurements.

Selenium stable isotope ratio measurements can provide insights into the processes occurring in the subsurface $[2,3]$. $\mathrm{Ab}$ initio calculations using density functional theory were executed to determine the amount of fractionation to be expected for selected subsurface processes. Laboratory experiments were conducted to compare the amount of fractionation with theoretical values.

Calculated values are in the higher end range of those reported in the literature for reduction. Pairing the $\mathrm{SeO}_{4}{ }^{2-}$ or $\mathrm{SeO}_{3}{ }^{2-}$ molecule with cations (such as $\mathrm{Ca}^{2+}$ ) lowers the overall expected isotopic fractionation, bringing it closer to abiotic laboratory results. This work supports Se stable isotope measurements as a tool in analyzing environmental data.

[1] Lemly 2004 Ecotox Environ Safe 59. 44-56. [2] Johnson 2012 Handbook of Environ Isotope Geochem Ch 9 155-175. [3] Basu et al. 2016 ES\&T 50. 10833-10842. 